\title{
ОСОБЕННОСТИ ТЕЧЕНИЯ ЭПИЛЕПСИИ И ЭПИЛЕПТИЧЕСКИХ СИНДРОМОВ У НЕДОНОШЕННЫХ ДЕТЕЙ В РЕЗИДУАЛЬНОМ ПЕРИОДЕ РАЗВИТИЯ
}

\author{
*Л.Е.Выговская, А.Р.Гайнутдинов \\ Казанская государственная медицинская академия, Казань, Россия
}

Эпилептический синдром у недоношенных детей сложен в диагностике и требует быстрой и адекватной тактики терапии. Форма эпилепсии и характер эпилептических приступов у недоношенных детей определяются сроком гестации и тяжестью общего состояния при рождении. Симптоматическая и идиопатическая формы эпилепсии характерны для пациентов с I-II ст. недоношенности, для глубоконедоношенных детей характерна условно - симптоматическая форма эпилепсии.

Ключевые слова: недоношенность, срок гестации, тяжесть состояния при рождении, эпилепсия, эпилептический синдром.

В мире насчитывается около 50 млн. больных эпилепсией $[1,3,8,9]$, в $75 \%$ случаев дебют заболевания приходится на детский возраст, при этом максимальная заболеваемость регистрируется до 10 летнего возраста [4,5]. Заболеваемость эпилепсией составляет 50-70 на 100000 человек, распространенность 5-10 на 1000 человек. Не менее одного припадка в течение жизни переносит 5\% населения, а у 20 $30 \%$ больных эпилепсия является пожизненным заболеванием [2,6]. По данным Международной противоэпилептической лиги, в Западной и Центральной Европе эпилепсией страдают 6 миллионов человек и количество больных в ближайшие 20 лет будет насчитывать около 15 миллионов [8,9].

Актуальность проблемы изучения эпилепсии у детей определяется двумя аспектами: 1) возникновение эпилептических пароксизмов значительно ухудшает прогноз психического и двигательного развития ребёнка $[1.2,7] ; 2)$ эпилепсии у детей, перенесших перинатальное повреждение мозга, часто представлены тяжёлыми формами с катастрофическим течением, резистентными к противосудорожной терапии, что усугубляет тяжесть инвалидизации больных $[5,6]$.

Выделение детей группы риска по формированию эпилепсии и эпилептических синдромов, а также определение прогноза течения приступов поможет решить вопрос о дифференцированном подходе к выработке тактики ведения пациента в каждом конкретном слу-

*e-mail: larisa-vigovskaia@rambler.ru чае. Всё вышеизложенное определяет цель предпринятого исследования.

Цель исследования - проследить характер эпилептических пароксизмов у недоношенных детей с различными сроками гестации в резидуальном периоде развития и разработать алгоритм их диагностики у данной категории пациентов.

Материал исследования. С признаками эпилептических пароксизмальных состояний наблюдалось 153 недоношенных ребенка в возрасте от 7 до 18 лет. В зависимости от тяжести состояния при рождении дети были подразделены на 2 группы: основную и группу сравнения.

В основной группе больных по поводу эпилептических пароксизмов наблюдался 101 человек, среди них пациенты с I ст. недоношенности (1 подгруппа) составили 36 (54\%) человек; со II ст. недоношенности (2 подгруппа) $40(49,3 \%)$ человек; с III и IV ст. недоношенности (3 и 4 подгруппы) - 18 (34,8\%) и 7 (32\%) человек соответственно. Все пациенты родились с признаками гипоксии, что расценивалось по шкале Апгар, как тяжелое (1-4б.), средней степени тяжести (5-6 б.) и легкой степени тяжести (6-7 б.) состояние.

Клинические проявления эпилепсии и эпилептических синдромов отмечались у 52 человек в группе сравнения, в их структуре пациенты с I ст. недоношенности (1 подгруппа) составили 33 (30,7\%) человека; со II ст. недоношенности (2 подгруппа) 15 (28\%) человек, с 
III ст. недоношенности (3 подгруппа) - 4 $(17,3 \%)$ человека, пациенты c IV ст. недоношенности с эпилепсией не наблюдались. Все пациенты данной группы родились в удовлетворительном состоянии.

В основной группе больных характер эпилептических приступов распределялся следующим образом: идиопатическая форма эпилепсии чаще всего отмечалась среди пациентов 1 подгруппы (11,64\%), у больных 2 подгруппы она наблюдалась в 1,23\% случаев; среди глубоконедоношенных детей в 3 и 4 подгруппах эта форма эпилепсии не встречалась $(\mathrm{p}<0,05)$.

Симптоматическая форма эпилепсии регистрировалась у 37,1\% пациентов в 1 подгруппе и у 43,1\% больных во 2 подгруппе, что также превышает аналогичные показатели у глубоконедоношенных больных в 3 и 4 подгруппах $(25 \%$ и $18,2 \%$ соответственно) $(\mathrm{p}<0,05)$.

Условно-симптоматическая форма эпилепсии была наиболее характерна для пациентов 4 подгруппы $(14 \%)(\mathrm{p}<0,05)$ (рис.1).
Фокальные приступы в несколько раз чаще регистрировались у пациентов 1 подгруппы $(27 \%)(p<0,05)$. В структуре парциальных пароксизмов простые и сложные приступы чаще всего возникали у пациентов 1 подгруппы (19,46\%); сложные приступы со вторичной генерализацией были наиболее характерны для пациентов 4 подгруппы $(9,1 \%)(p<0,05)$.

Первично - генерализованные типы припадков примерно с одинаковой частотой наблюдались среди всех категорий недоношенных больных в основной группе.

Тонико-клонические приступы преобладали у пациентов 2 подгруппы (14,8\%).

Миоклонические приступы в несколько раз чаще возникали среди пациентов 2 подгруппы (2,99\%); абсансные формы эпилепсии были наиболее характерны для пациентов 1 подгруппы $(8,96 \%)(\mathrm{p}<0,05)$.

Синдром Веста является преобладающей формой эпилепсии среди глубоконедоношенных больных в 3 и 4 подгруппах $(17,4 \%$ и $18,35 \%$ соответственно) $(\mathrm{p}<0,05)$.

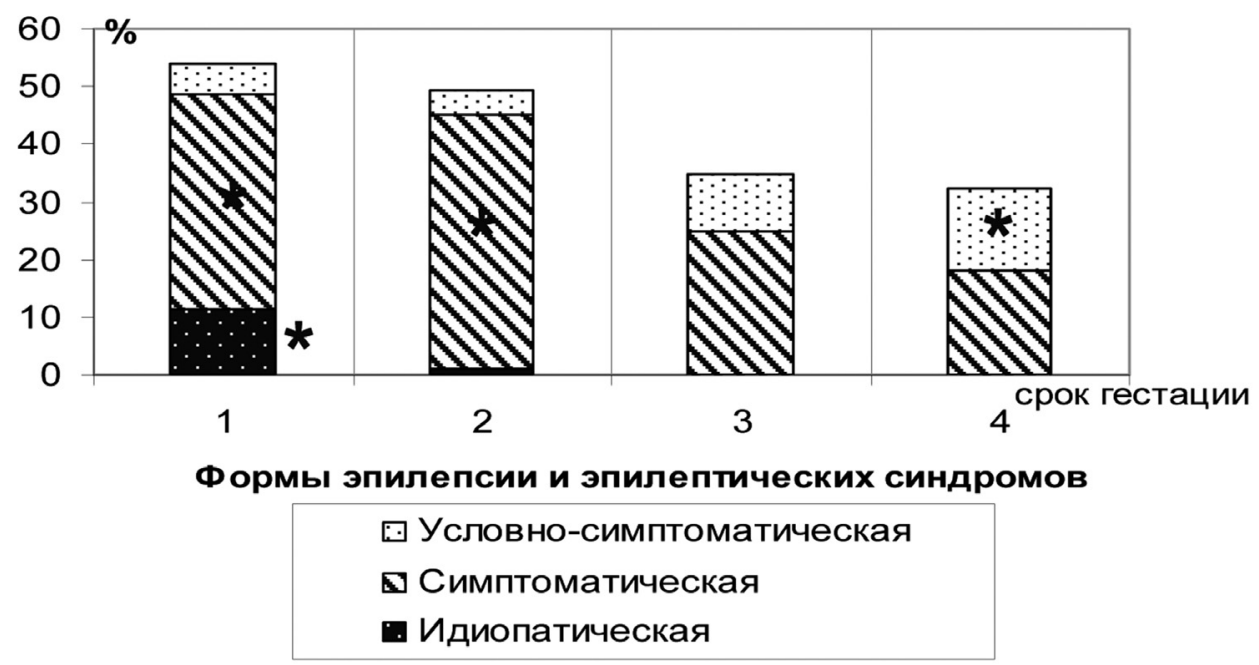

Рис.1 Распределение основных форм эпилепсии и эпилептических синдромов среди недоношенных больных в резидуальном периоде развития в основной группе (в \%) $(1,2,3,4$ - степени недоношенности; *-р<0,05)

Структура эпилептических приступов в группе сравнения имела свои особенности. Идиопатическая форма эпилепсии в несколько раз чаще отмечалась среди пациентов 1 подгруппы - 10\%, чем среди больных во 2 и 3 подгруппах $(1,9 \%$ и 4,3\% соответственно) $(\mathrm{p}<0,05)$.

Симптоматическая форма эпилепсии была наиболее характерна для пациентов первых двух подгрупп (15,9\% и 18,8\% соответствен- но) $(\mathrm{p}<0,05)$. Условно - симптоматическая форма эпилепсии с равной частотой регистрировалась среди всех категорий недоношенных больных группы сравнения (рис.2).

Простые и сложные парциальные приступы в несколько раз чаще отмечались у пациентов 1 подгруппы (10,5\%), чем у больных во 2 и 3 подгруппах (3,8\% и 4,3\% соответственно) $(\mathrm{p}<0,05)$. Пароксизмы со вторичной гене- 
рализацией с одинаковой частотой регистрировались среди всех категорий недоношенных больных (4\%; 3,7\% и 4,3\% соответственно 1-3 подгруппам).

Первично - генерализованные приступы примерно с одинаковой частотой отмечались у всех категорий больных $(16,2 \%, 20,3 \%, 13 \%$ детей в 3 подгруппах соответственно).

Тонико-клонические пароксизмы преобладали в клинике эпилептических нарушений у пациентов 2 подгруппы (11\%), в то время, как среди больных в 1 и 3 подгруппах они отмечались у 5,7\% и 8,7\% больных соответственно $(\mathrm{p}<0,05)$.

Абсансы были наиболее характерны для 1 подгруппы больных - 3,8\%; среди остальных недоношенных пациентов данный вид пароксизмов не отмечался.

Синдром Веста с преобладающей частотой регистрировался среди пациентов 3 подгруппы $(4,3 \%)$, среди больных 1 подгруппы не наблюдался $(\mathrm{p}<0,05)$.

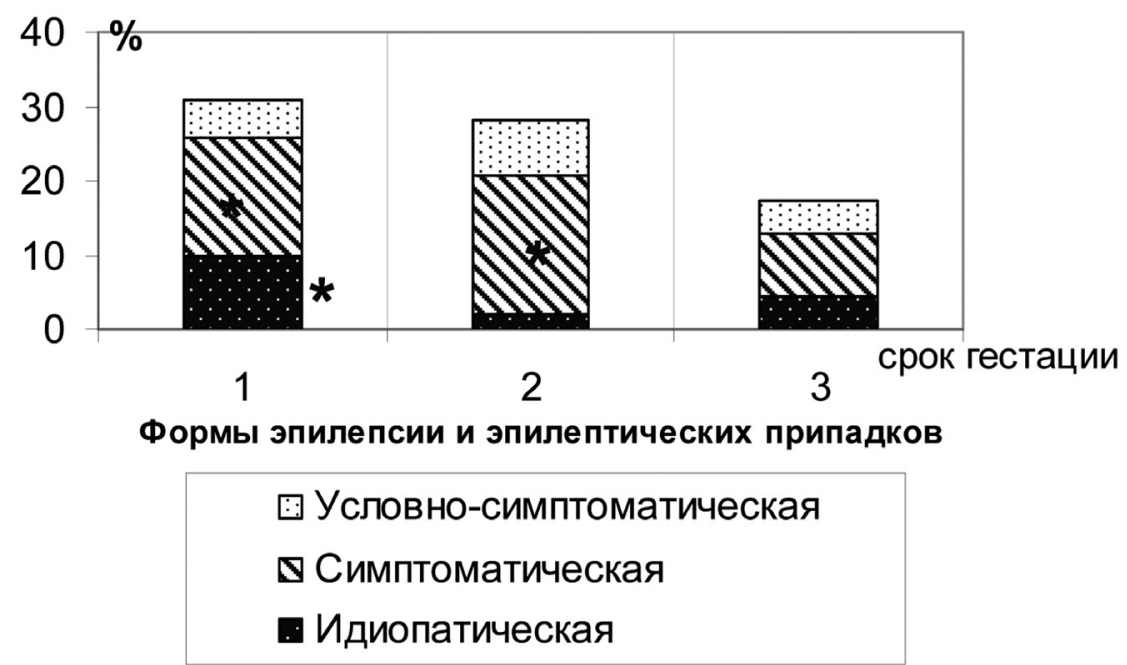

Рис.2 Распределение основных форм эпилепсии и эпилептических синдромов у недоношенных детей резидуальном периоде развития в группе сравнения (в \%) $(1,2,3,4$ - степени недоношенности; *-р<0,05)

\section{Выводы}

1. Для пациентов с I ст. недоношенности (1 подгруппа), родившихся как в удовлетворительном состоянии, так и в условиях гипоксии, наиболее характерны идиопатическая и симптоматическая формы эпилепсии; в структуре фокальных приступов преобладают простые и сложные пароксизмы, среди первичногенерализованных припадков чаще встречаются абсансные формы эпилепсии.

2. Для пациентов со II ст. недоношенности (2 подгруппа), родившихся как в удовлетворительном состоянии, так и в условиях гипоксии наиболее характерна симптоматическая форма эпилепсии; среди первично-генерали-

\section{СПИСОК ЛИТЕРАТУРЫ}

1. Белоусова Е.Д. Факторы риска, тактика лечения и прогноз судорожного синдрома и эпилепсии у детей с детским церебральным параличом: Автореф. дис.... докт. мед. наук /Е.Д. Белоусова/.- М., 2006. - 49с.

2. Бадалова С.Т. Диагностика и лечение психо- зованных пароксизмов превалируют тоникоклонические и миоклонические припадки.

3. У глубоконедоношенных пациентов с III и IV ст. недоношенности (3 и 4 подгруппы) чаще всего отмечается условно-симптоматическая форма эпилепсии, для пациентов с IV ст. недоношенности в структуре парциальных приступов наиболее характерны сложные пароксизмы с вторичной генерализацией; у глубоконедоношенных больных отмечается наиболее тяжелая и прогностически неблагоприятная форма эпилепсии, характеризующаяся наличием фармакологической резистентности и развитием эпилептической энцефалопатии - синдрома Веста.

моторного развития у детей с эпилепсией раннего возраста: Автореф. дис.... канд. мед. наук /С.Т. Бадалова /.-М., 2006. - 18c.

3. Бадалян О.Л. Возрастные особенности эпилепсии у детей и подростков: Автореф. дис.... докт. 
мед. наук /О.Л. Бадалян/.- М., 2004. - 56с.

4. Прусаков В.Ф. Детская эпилепсия и ее лечение / В.Ф. Прусаков // Неврологический вестник им. В.М. Бехтерева. - 2004. - Том XXXVI. - вып.1-2. - С. 82-85. 5. Васильева О.А. К вопросу о нейроиммунных расстройствах и их роли в терапии больных с резистентными формами эпилепсии / О.А. Васильева, Л.В. Липатова, С.А. Громов // Сибирский вестник психиатрии и наркологии. - 2006. №41(прил.). - С. 64-66.

6. Воронкова К.В. Эволюция эпилепсии и трансформация эпилептических приступов: Автореф. дис.... докт. мед. наук /К.В. Воронкова /.-М., 2007. - 51с.
7. Зенков Л.Р. Корковые дисплазии и эпилепсия: патофизиологические, диагностические и терапевтические аспекты / Л.Р. Зенков // Неврологический журнал. - 2006. - №1. - С. 56-59.

8. Korenke G.C. Severe encephalopathy with epilepsy in an infant caused by subclinical maternal pernicious anaemia: case report and review of the literature / G.C. Korenke, D.H. Hunneman, S. Eber [et al] // Eur J Pediatr. - 2004. - № 4-5.- P196-201

9. Sanger T.D. Interactions between two different inhibitory systems in the human motor cortex / T.D. Sanger, R.R. Garg, R.Chen // J. Physiol. - 2001. Vol. 530. - №2. - P.307-317

\title{
XÜLASə
}

\section{VAXTINDAN ӘVVӘL DOĞULAN UŞAQLARDA INKKIŞAFIN REZIDUAL MORHOLOSINDӘ EPILEPSIYA VӘ EPILEPTIK SINDROMLARIN GEDISŞININ XÜSUSIYYYOTLORİ}

\author{
L.E.Viqovskaya, A.R.Qaynutdinov \\ Kazan Dövlat Tibb Akademiyası, Kazan, Rusiya
}

Vaxtından əvvəl doğulmuş körpələrdə epileptik sindromun diaqnostikası mürəkkəbdir və sürətli və adekvat müalicə taktikası tələb edir. Belə uşaqlarda epilepsiyanın forması və epileptik tutmanın xarakteri hestasiyanın müddəti və doğuş zamanı ümumi vəziyyətin ağırlığı ilə təyin edilir. Epilepsiyanın simptomatik və idiopatik formaları I-II mərhələ vaxtından əvvəlki doğuş zamanı xəstələr üçün xarakterikdir, ağır dərəcəli vaxtından əvvəl doğulmuş uşaqlarda epilepsiyanın şərti simptomatik forması xarakterdir.

Açar sözlər: vaxtından əvvəl doğulma, hestasiya müddəti, doğularkən vəziyyətin ağırlığı, epilepsiya, epileptik sindrom.

\section{SUMMARY}

\section{FEATURES OF EPILEPSY AND EPILEPTIC SYNDROMES IN PREMATURE CHILDRENS IN THE RESIDUAL PERIOD OF DEVELOPMENT}

\author{
L.E.Vygovskaya, A.R.Gaynutdinov \\ Kazan State Medical Academy, Kazan, Russia
}

Epileptic syndrome in premature infants is difficult to diagnose and requires prompt and adequate treatment tactics. The form and nature of epilepsy seizures in premature infants determined gestational age and the severity of the general condition at birth. Symptomatic and idiopathic epilepsy characteristic of patients with I-II prematurity for severe premature infants characterized conditionally symptomatic form of epilepsy.

Keywords: prematurity, gestational age, severity of the condition at birth, epilepsy, epileptic syndrome.

Redaksiyaya daxil olub: 11.04 .2013

Çapa tövsiya olunub: 09.04.2013

Rayçi: R.K.Şiraliyeva, t.e.d., prof. 